\title{
Sistemas Prioritários Para a Administração do Desenvolvimento
}

WILBURG JIMÉNEZ CASTRO (")

Técnico das Nações Unidas para os Programas do Desenvolvimento. Ex-Diretor do ICAP (Instituto Centro-americano de Administração Pública).

Tradução de Araújo Cavalcanti

SUMARIO: I - O conceito de "sistema" para os processos prioritários da administração do desenvolvimento. II - Objetivos e características dos sistemas prioritários para a administração do desenvolvimento. 1. O processo das decisōes executivas. 2. A natureza das decisőes. III - Os sistemas prioritários para a administração do desenvolvimento. A) Os sistemas centrais assessôres. 1. O sistema de planificação. 2. O sistema de orçamento. 3. O sistema de modernização administrativa. 4. O sistema de pessoal. B) Os sistemas centrais auxiliares. 5 . O sistema estatístico. 6. O sistema de contabilidade pública. 7. O sistema de compras, abastecimento e armazenamento.

I - O CONCEITO DE "SISTEMA" PARA OS PROCESSOS PRIORITARIOS DA ADMINISTRAÇAOO DO DESENVOLVIMENTO.

Por "sistema" compreende-se o conjunto de órgãos, princípios e normas sôbre uma matéria, tão estreitamente enlaçados ou coordenados entre si, que constituem um todo indivisivel, apesar da relativa independência funcional ou operativa que possam ter as suas partes componentes. Essas partes atuam com uma mesma orientação e satisfazem a um objetivo comum.
O sistema é, assim, um todo organizado e articulado, não acumulado,

(*) Wilburg Jiménez Castro é Técnico do Programa das Nações Unidas para o Desenvolvimento. Foi Diretor dêsse Projeto e exerceu, igualmente, a chefia do ICAP (Instiuo Centro-americano de Administração Pública). $O$ documento foi preparado para o Seminário sôbre Aspectos Administrativos da Execuçăo de Planos de Desenvolvimento, realizado em Santiago (Chile), de 19 a 28 de fevereiro de 1968 . Os critérios e idéias do autor não constituem um pronunciamento oficial das Naçōes Unidas. 
cujo crescimento se faz de dentro para fora tornando cada uma das partes mais forte e adequada às suas finalidades - individuais ou coletivas, - sem alterar a proporção de cada uma delas dentro do conjunto.

Nos sistemas não existem unidades isoladas; há um "órgão central" cujas atividades são importantes para orientar seu funcionamento, mas, co-existiräo outras partes componentes: as que se denominam "setores".

Esta concepção se encontra nos sistemas circulatório, nervoso, respiratório, digestivo, reprodutivo, ósseo, muscular etc., do corpo humano, assim como no sistema planetário do universo, os quais têm as características antes indicadas. Pode-se, também, aplicar a todos os sistemas administrativos, tais como o educativo, - de saúde, o econômico, o de segurança social etc., e àqueles que se analisam neste documento como "sistemas prioritários para a administração do desenvolvimento".

Para obter o desenvolvimento integral, os mencionados sistemas prioritários têm grande transcendência, pois criam uma série de estímulos; formulam normas gerais de aplicação descentralizada e coordenada; racionalizam as estruturas e os procedimentos administrativos; inter-relacionam os trabalhos de vários dêles e a política com a administração; permitem o meIhor uso possível dos escassos recursos humanos qualificados, financeiros e materiais, logrando, assim, obter maior eficiência; motivam, da melhor maneira, a participação $\theta$ as atividades do pessoal.

Infelizmente, essa concepção de "sistemas" não foi compreendida nem utilizada em muitos países, e em contraposição, se organizaram órgãos centrais de planificação, de pessoal, de orçamento, de modernização administrativa, de contabilidade, de estatística, de compras, de abastecimento, de armazenamento, etc., como partes da organização tradicional do govêrno.

Outras vêzes, para alguns dêles se criaram unidades setoriais em seu campo; mas ao não atuar dentro do critério de sistemas - senão de forma isolada e mais relacionada com os objetivos próprios do ministério, da dependência ou da instituição descentralizada a qual pertencem, - desvirtuam as vantagens inerentes a um sistema.

Em alguns casos, recorreu-se à criação de um superorganismo, usualmente como secretaria técnica ou administrativa da Presidência da República, para organizar tôdas essas funções.

A esta última forma de organização e às experiências de vários países refere-se com tôda propriedade o Lic. José Maria Jácome (Assessor em Administração Pública da Comissão Econômica para a América Latina, das Nações Unidas), no documento "A Planificação Administrativa no Processo de Planificação do Desenvolvimento Econômico e Social".

É oportuno destacar o que êle qualifica como um esquema avançado de institucionalização da planificação administrativa, através da constituição de um corpo de "estado-maior" para atender trabalhos de assessoria e algumas atividades auxiliares, com caráter ".... Multidisciplinar, de grande ductibilidade, que poderia ser um centro dinâmico de promoção do desen- 
volvimento econômico."1 Neste mesmo documento se diz que:

"A integração das funções de planificação econômica, planificação administrativa, administração de pessoal, administração orçamentária e estatísticas, poderia proporcionar ao mais alto executivo nacional os instrumenmentos institucionais mais importantes para elaborar planos, programas e projetos, executá-los, controlá-los e avaliá-los. É, sem dúvida alguma, uma concepção de coordenação funcional que merece analisar-se com demorada atenção... as vantagens de um semelhante organismo são teòricamente óbvias... Em que pese a seu atrativo teórico, esta forma de institucionalização da planificação administrativa deve enfrentar dificeis problemas práticos de caráter político e operacional. O aparecimento de um organismo técnico de grande influência nas decisões de política governamental e com capacidade para medir o progresso dos programas estatais em todos os setores é ressentido pelas tradicionais estruturas do setor público, acostumadas, até então, a uma certa independência de decisão e operação.

A coordenação que se trata de introduzir é, freqüentemente, um fator moderador da liberdade de ação anterior. O organismo que trata de aplicá-la encontra, muitas vêzes, a resistência e a desconfiança dos organismos administrativos tradicionais. A concentração em um só organismo das funções de "estado-maior" e a enorme influência que elas têm no processo da tomada de decisões de alta política também provocam o temor de que essas Secretarias Técnicas se convertam em organismos hie- ràrquicamente superministeriais. Não se tem uma clara noção de que sua autoridade é assessôra e auxiliar e teme-se que se possa converter em decisória e executiva. A integração destas funções em um só organismo facilita, ademais, a concentração de fogo nas fôrças que se opõem a estas novas funções ordenadoras. Em caso de conflito é mais fácil atacar um só organismo, culpando-o ou responsabilizando-o por todos os problemas existentes ou imaginários, do que a vários organismos distintos."2

Em aditamento às observaçőes do Lic. Jácome é necessário e oportuno considerar os seguintes aspectos:

1 - A centralização em um só organismo das diferentes atividades de planificação, orçamento, pessoal, obriga a contar com um numeroso e heterogêneo funcionalismo, além de muitos recursos econômicos.

Essa organização centralizada dificulta por outro lado a satisfação dos objetivos próprios de cada uma das unidades; quando concentradas essas atividades e não inter-relacionadas, perdem a necessária e relativa independência funcional que hão de ter, não importa como estejam hieràrquicamente coordenadas. Tal situação se agrava quando se adicionam os trabalhos de modernização administrativa que de um ponto de vista operativo são de natureza diferente das tarefas de planificação administrativa e que hão de estar necessàriamente relacionadas com tôdas aquelas atividades, como, também, com as outras

1. Lic. José Maria Jácome, “A Plantficaçâo Administrativa no Processo da Planificaçăo do Desenvolvimento Econômico e Social", CEPAL, Santiago, Chile, 1967.

2. J. M. Jácome, op. cit., págs. $17 / 8$. 
funções prioritárias de informação contábil e estatística e de compras, abastecimento e armazenamento.

2 - E necessário que cada uma daquelas atividades se organize em "sistemas", segundo sua própria natureza.

Dentro de cada um dêsses "sistemas" há um órgão central que tem a responsabilidade de coordenar tôdas as partes componentes de seu próprio sistema - através de normas técnicas e de relações que posteriormente serão analisadas.

Integram, além disso, cada um dos sistemas, unidades setoriais localizadas nos diferentes ministérios, dependências, repartições, instituições autônomas, organismos regionais e governos locais que o mereçam.

As unidades setoriais localizadas no govêrno central operam dentro da estrutura formal do mesmo e suas relaçōes com a unidade central se fazem através dos canais hierárquicos regulares, isto é, do superior do organismo, o qual, por sua vez, através das mesmas relações para cima, recebe de seus superiores as normas técnicas para a atuação das respectivas unidades setoriais. Evitam-se assim as dualidades de mando que se apresentam freqüentemente na organização funcional, subjetiva ou de mando especializado, ao estabelecer um só canal hierárquico de relações formais.

3 - Cada um dos sistemas prioritários para a administração do desenvolvimento, com relação aos outros, há de atuar com relativa independência, mas, também, de forma inter-relacionada. A planificação econômica e social, por si mesma, não é e não há de atuar como um processo que res- trinja ou "englobe" nêle as outras atividades, tais como as de orçamento, de pessoal, de modernização administrativa, de estatística, etc.

Estabelece as metas globais do desenvolvimento com base em seus próprios elementos de juizo e com os que os outros sistemas the dão, e fixa assim um marco de atuação a mais realista possivel dentro do qual se hão de desenvolver, de acôrdo com suas próprias concepçöes e iniciativas.

Igualmente, através do orçamento por programas e atividades se financia a realização dos planos de curto prazo, estabelecendo ademais as bases do funcionamento dos planos de médio e longo prazos e se avalia, periòdicamente, como se atenderam os primeiros e se reajustam as metas dos outros. Não é então o orçamento um obstáculo para a planificação, ou para a aplicação de normas de pessoal, etc., senão um processo que melhormente as canaliza para a ação, através do financiamento que por seu intermédio se Ihes outorga.

Tampouco as normas centrais de pessoal, de contabilidade, de estatistica, de compras, abastecimento $\theta$ armazenamento, e de modernização administrativa podem atuar racional $\theta$ efetivamente de forma isolada.

Tôdas elas têm de ser concebidas e aplicadas como processos administrativos interdependentes dentro de sistemas, pois é muito difícil alcançar êxito, por exemplo, com um processo de modernização de estruturas e procedimentos administrativos quando êste não conta com o devido respaldo financeiro outorgado pelo orçamento. Nem se consegue sucesso quando o pessoal que val condicionar a mu- 
dança não está suficientemente motivado por planos coordenados de modernização e de sistemas de mérito.

4 - Pela natureza das funções $e$ objetivos que têm cada um dêsses sistemas prioritários, suas unidades centrais podem agrupar-se em duas categorias diferentes, as quais determinam ademais sua melhor localização, relação hierárquica $\theta$ de coordenação.

a) As unidades centrals de planificação, de modernização administrativa, de orçamento e de pessoal são "serviços de estado-malor" e como tais hão de estar às ordens e na relação hierárquica direta da Presidêncla da República. Têm funções: a) assessôras; b) de informação; c) de supervisão por incumbência do Chefe do Poder Executivo e d) de infiltração de idélas, pela autoridade técnica que possuem e pela capacidade de persuasão que têm de desenvolver sôbre as unidades setoriais componentes do sistema.

Não têm formalmente relações hierárquicas com os outros membros do Poder Executivo, nem recebem ou dão ordens, senão que atuam sempre diretamente para cima por meio de conselhos, relatórios, recomendações, etc. Evita-se, assim, a dualidade de mando que algumas vêzes ocorre quando essas unidades normativas centrais de assessoria assumem ou desempenham funções auxillares de linha.

Com a relação direta com o Chefe do Poder Executivo - e não através de algum ministro ou funcionário de alta hierarquia ou assessoramento superior -, evita-se a transferência a um cargo distinto ao do Presidente.
Por outro lado, logra-se uma estreita relação entre a política e a administração técnica, juntando ambas no nivel presidencial em um único centro de decisões.

Para facilitar o intercâmbio de Idéias, o sentido de participação, a obtenção de um esprit de corps e critérios atualizados de ação sôbre planificação e modernização administrativa, é aconselhável organizar outros órgãos assessôres da Presidência, para planificação e modernização administrativa e cujos trabalhos de secretaria técnica estão nas respectivas agências centrais. Êstes órgãos assessôres são pluripessoais e nêles podem participar vários ministros e funcionários de organismos descentralizados. Também podem colaborar profissionals e elementos do setor privado e assessôres internacionais. As comissões são presididas pelo próprio Presidente e as conclusões a que se chega nas deliberaçōes e estudos têm caráter de recomendações para êle $\theta$, como tals, pode aceitá-las ou não.

Algumas das experiências positivas que se conseguiram na América Latina tornam recomendável a existência dêsses órgãos centrais assessôres. De acôrdo com alguns dados disponiveis, doze das dezoito unidades centrais de planificação que existem têm alguma espécie de junta, conselho ou comissão similar e quatorze dessas unidades centrais de planificação estão no âmbito da Presidência da República.

b) As unidades centrais dos sistemas de estatistica, de contabilidade e de compras, abastecimento e armazenamento têm funções de "serviços auxiliares", e não atividades com caráter de assessoramento. A coorde- 
nação dessas unidades centrais auxiliares deve fazer-se por um funcionário político ou administrativo de alta hierarquia que esteja em relação direta imediata com o Presidente da República e que participe de seu gabinete, pois assim é mais fácil e exeqülvel que suas normas possam ter aplicação no resto da administração estatal, central e descentralizada.

c) As normas de operação para cada um dêsses sistemas terăo de ser reguladas técnica e legalmente para que sua aplicação seja obrigatória. Tal é o caso das normas que se hão de obedecer e seguir-se para as investigações, recopilações, registros e publicações estatísticas e contábeis; para as aquisições de materiais; para a contratação de serviços; para as licitações e adjudicações; para o armazenamento, etc.

Também as atividades dos sistemas de planificação, orçamento, modernização administrativa, pessoal, estatística deverão contar com uma base legal, sendo recomendável a promulgação de leis gerais a respeito e de regulamentos constitucionais.

5 - Em cada um dos ministérios, dependências e organismos funcional e geogràficamente descentralizados que o mereça, devem se localizar unidades setoriais de planificação, orçamento, modernização administrativa, pessoal, estatística, contabilidade, compras, abastecimento e armazenamento. Elas são partes integrantes do respectivo ministério, repartição e organismo e, como tais, têm relações formais sòmente com o hierarca máximo da entidade, pois neste recaem as decisões do Chefe do Poder Executivo, através de ordens administrativas ou de coordenação institucional.
6 - A estrutura administrativa de cada sistema há de ser complementada com procedimentos adequados em condições de agilizar e tornar dinâmico o seu funcionamento.

\section{II - OBJETIVOS E CARACTERISTI- CAS DOS SISTEMAS PRIORI- TARIOS PARA A ADMINISTRA- ÇÃO DO DESENVOLVIMENTO. \\ 1. O processo das decisões exe- cutivas}

Um dos principais objetivos dos sistemas prioritários a que se tem feito reiteradas alusões neste documento é colaborar efetivamente no processo de decisões executivas para que elas se tomem através de:

I - O conhecimento dos fatos (estatísticas e contabilidade);

II - sua adequada canalização através de ordens, critérios e financiamento (política, planos, programas, e orçamento);

III - sua alocação a instituições $\theta$ pessoas em um marco dinâmico e relacionado com os objetivos, para que as estruturas e os procedimentos administrativos permitam o cumprimento das políticas e dos planos e programas (modernização administrativa);

IV - a plena participação de todo o pessoal do setor público, como conseqüência de normas adequadas de recrutamento, seleção, classificação, avaliação, adestramento no serviço, treinamento, remunerações, penalidades, sanções, aposentadoria, etc., e de boas relações humanas, esprit de cor ps, disciplina, moral, eqüidade, lealda de, capacidade realizadora, iniciativa, estabilidade (administração de pessoal, 
com um enfoque humano e não apenas instrumental);

V - racionalização das inversões ou gastos que se fazem em bens imóveis, equipamento, materiais, conservação, armazenamento, etc. (compras, abastecimento e armazenamento).

\section{A natureza das decisões}

As decisões são estratégicas ou táticas. Entre as decisões de natureza estratégica e as de caráter tático que têm de ser tomadas no âmbito da administração do setor público, as primeiras estão reservadas aos níveis superiores de decisões políticas dentro das esferas de competência do Poder Executivo e do Poder Legislativo.

Essas decisões estratégicas devem corresponder, em última instância, ao Chefe do Poder Executivo, naquelas matérias que, de acôrdo com o ordenamento constitucional de cada país, estão compreendidas entre suas atribuições privativas.

Dada a complementaridade dos conceitos em referência e sua estreita inter-relação na prática, e considerada da mesma maneira a natureza das funções e prerrogativas daqueles podêres, há de se observar que os que têm a responsabilidade de exercê-los, freqüentemente devem tomar decisões igualmente de caráter tático.

Nada obstante, não varia, nem se nega a responsabilidade fundamental, que é a de tomar decisões de caráter estratégico.

As unidades centrais dos sistemas prioritários têm uma participação direta e de extraordinária importância na formulação das diretrizes, orientações, propostas, marcos ou metas que haverão de constituir objeto daquelas de- cisões estratégicas, mediante a assessoria técnica, que devem proporcionar às autoridades responsáveis pelas decisões políticas. Pode-se considerar, então, que o trabalho que realizam em tal sentido, orientado para o estabelecimento de uma estratégia, é, em si mesmo, um trabalho de natureza estratégica. Sem embargo, a decisão que transforme seus esquemas, propostas e formulações em uma estratégia definida e determinada, sòmente pode corresponder àqueles outros niveis anteriormente assinalados.

Em seu estrito âmbito funcional e institucional, cada uma dessas unidades centrais define, estabelece e executa a estratégia e os procedimentos táticos pertinentes à sua própria atuação, assim como também as atuações das unidades setoriais do sistema que estão subordinadas ao mesmo processo.

Deve ser enfatizado que a estratégia e as táticas que se estabeleçam nas unidades centrais, nas unidades setoriais e em tôdas as unidades lineares da organização do setor público, através dos canais formais de autoridade e coordenação, terão de estar por assim dizer condensadas e estreitamente vinculadas à realização da estratégia e aos procedimentos táticos objeto das decisões politicas superiores, e orientadas para os avanços, conquistas, realizações e metas que por elas se definem.

A não ser assim, não se pode falar, com rigor, de um sistema.

As táticas que se utilizem ou estabeleçam, terão de se expressar dessa forma, através da operação do sistema nos diversos ministérios ou entidades administrativas de diversa natureza, frente às conjunturas ou circunstâncias 
que se apresentam, e tenderão, sempre e obrigatòriamente, a que se concretizem as políticas e objetivos nacionais básicos, contemplados nas decisões estratégicas tomadas nos níveis anteriormente indicados, em um marco mais amplo de atividades, de podêres e decisões.

\section{III - OS SISTEMAS PRIORITÁRIOS PARA A ADMINISTRAÇÃO DO DESENVOLVIMENTO}

A análise das características mais importantes de cada um dos sete sistemas, definidos como prioritários para a ação administrativa para o desenvolvimento, confirma a necessidade de sua organizaçäo institucional e da inter-relação que deverão manter.

A seguir apresentam-se de maneira resumida os traços mais característicos de cada um dêles:

A. Os sistemas centrais assessôres

1. O sistema de planificação

A planificação é um processo racionalizador e indispensável à ação do desenvolvimento. É um dos melhores meios com que o Estado conta para prever, promover e canalizar instrumentalmente o melhoramento cultural, político, econômico e social a que. tende o desenvolvimento integral. É a manifestação de uma vontade de mudança e transformação implícita nesse processo de desenvolvimento.

A planificação tem sido uma necessidade sentida desde longos anos no setor público e a ela se referia, com tôda propriedade, um destacado politico dos séculos XVI e XVII, nos seguintes têrmos: ${ }^{3}$

"A natureza dos negócios do Estado requer de quem se dedica aos assun- tos públicos, meditar, com freqüência, para prever o que pode acontecer e traçar planos que permitam unir, sem prejuizo, o presente com o futuro".

A planificação há de ter uma orientação prática e real e não acadêmica ou teórica, para que ative, acione, deliberada, racional e permanentemente, todos os processos de ação para - desenvolvimento, originados dentro e fora do setor público.

As experiências de muitos países revelam a necessidade de vincular mais estreitamente a elaboração de diagnósticos $\theta$ a determinação e formulação dos planos de desenvolvimento, com a planificação administrativa das atividades que hão de permitir sua implementação e buscar melos mais adequados para que no processo de planificação participem, de forma mais ativa, funcionários e empregados públicos e, também, os principais componentes do setor privado, dentro de seu respectivo âmbito de atividades.

Existem planos de desenvolvimento na maioria dos países latino-americanos, cujas características e natureza variam, assim como o grau de implementação que possuem. Em muitos casos êsses planos não foram cabalmente executados, entre outras razões porque, ao não serem compatíveis com as políticas e não disporem dos melos estruturais, processuais e administrativos para fazê-los ou torná-los operantes, permaneceram em documentos ou projetos não realizados. Ficaram no papel.

3. Louis du Plessis, Cardeal Richelieu, citado por Pierre Massé, "Planejamento e Administraçăo", vol. II, BIRF, Washington. 
Existe, ademais, em vários países, resistência à planificação da parte de alguns setores importantes de poder e não se conhece suficientemente, de maneira generalizada, o significado $e$ as vantagens da planificação. Mas, fol reconhecido que ... "a iniciativa individual exclusiva e o simples jôgo da concorrência não bastariam para assegurar o êxito do desenvolvimento... Os programas são necessários para animar, estimular, coordenar, suprir e integrar4 a ação dos indivíduos e dos corpos intermédios. Cabe aos podêres públicos escolher e ver o modo de impor os objetivos que se há de propor, as metas que urge fixar, os melos para atingi-las, estimulando, ao mesmo tempo, tôdas as fôrças agrupadas nesta ação comum."5

A ausência de uma adequada institucionalização da planificação em vários paises tem sido outro fator limitante.

Não basta contar com um órgão central e com algumas unidades setoriais, mas sim o estabelecimento de um sistema com as características anteriormente indicadas, a fim de que a planificação seja um processo ativador e para evitar que suas ações sejam neutralizadas pelos grupos de interêsse e de pressão.

A planificação e a modernização administrativas são dois processos diferentes em conteúdo e natureza. Mas ambos hăo de marchar juntos para os propósitos do desenvolvimento, considerando-se que a primeira é ao mesmo tempo um princípio e um processo para a segunda e a modernização administrativa oferece o meio institucional e humano mediante o qual a planificação se faz operativa.
Em tal sentido a planificação e a modernização administrativa são complementares e a prática demonstrou que:

“... nos últimos anos a introdução das novas idéias de planificação e a formulação de planos deram maior atualidade ao estudo dos problemas administrativos. As primeiras e mais graves dificuldades com que se defrontou no funcionamento dos sistemas de planificação latino-americanos e na execução dos programas de desenvolvimento, têm sido as deficiências da atual administração pública quanto a conceitos, tradições, estrutura $\theta$ funcionamento, que, em muitos casos, são incompativeis com o processo de mudança econômica e social. Por êste motivo, a planificação do desenvolvimento e a reforma se consideram atualmente como complementares $\theta$ interdependentes. Nos círculos planificadores se expressa, com maior clareza, que nunca fol tão grande quanto agora a necessidade de que a maquinaria administrativa seja um elemento de importância cardial a fim de que se possa obter os fins do desenvolvimento econômico e social.

... Pode afirmar-se que na América Latina a planificação do desenvolvimento foi fator decisivo para inicio de grandes transformaçōes administrativas. Importantes programas de modernização administrativa se inspiraram nos últimos anos nas agências ou órgãos de planificação nacional, chegando-se, em alguns casos isolados, a inclui-los como parte relevan-

4. "Mater et Magistra", AAS 53, 1961. 5. Carta Encíclica de Sua Santidade Paulo VI, "Populorum Progressio" (sôbre o Desenvolvimento dos Povos, Vaticano, 1967). 
te dos planos gerais de desenvolvimento."6

Como parte importante da institucionalização do processo planificador se devem buscar os meios que permitam estabelecer uma estreita vinculação entre os organismos técnicos de planificação $\theta$ os que devem tomar sob sua responsabilidade a execução dos planos.

As planificações global e setoriais têm de se concretizar em projetos operativos específicos, o que atualmente sucede com muito pouca freqüência e tem sido um dos fatôres que limitaram a execução dos planos. Outro problema é o seguinte: não se utilizam, suficiente e convenientemente, para a execução dos planos, os instrumentos de política econômica tais como os mecanismos monetários, crediticios, tributários, etc. É conveniente que se faça um maior esfôrço para superar tais limitações.

Os planos têm de difundir-se tăo amplamente como seja possivel para assegurar a participação de todos os setores que, direta ou indiretamente, são afetados pela planificação.

Quando a planificação não tem a necessária e estreita vinculação com - processo de formulação de políticas, isola-se de quem tem o poder de decisão superior, circunscrevendo a planificação a aspectos de caráter econômico e de natureza muito técnica e teórica, que restringem as relações entre os políticos $\theta$ os funcionários responsáveis pela ação. Isso contribui para que tampouco geralmente exista a necessária vinculação entre a planificação administrativa e a determinação e formulação de planos de desenvolvimento, que freqüentemente ficam nas metas não atingidas e nos programas não executados: ou seja, permanecem no papel.

A institucionalização da planificação requer um pessoal preparado e motivado.

Sem pessoal preparado é muito difícil satisfazer os requisitos de um processo racionalizador altamente técnico e que exige profissionalização em diferentes campos cientificos, pois a planificação não é apenas a responsabilidade de um único grupo profissional - chamem-se êstes economistas, administradores, advogados, engenheiros, etc. - senão de todos êles, atuando com um critério de equipe interdisciplinar e interprofissional, no qual também deverão participar todos os funcionários e empregados públicos, indistintamente de sua formação, experiência ou cargo, ou do âmbito central ou setorial aonde trabalham.

Deve existir uma relação intima $\theta$ harmônica entre os recursos humanos disponíveis para a planificação $e$ os programas de formação profissional $e$ de adestramento técnico no serviço, adicionalmente aos outros aspectos instrumentais peculiares a uma boa administração de pessoal.

E óbvio que um funcionalismo público bem preparado se apresenta com uma melhor capacidade intelectual e anímica para participar plenamente dêsse processo.

Um funcionalismo público preparado terá também maior receptividade para captar e fazer suas as grandes metas do processo de desenvolvimento inte-

6. Lic. José Maria Jácome - "Problemas da Administraçáo Pública nos Países da América Latina", 1966 (Doc. das Naçőes Unidas). 
gral, no qual êsse pessoal não é sòmente um fator isolado senão, igualmente, parte atuante e fim do mesmo. O homem a serviço do Estado constitui o elemento principal que condicionará o processo de transformação, o qual iniciar-se-á internamente na mente e no sentimento de cada um, para logo ser convivido com os outros partícipes dessas atividades e com os usuários alheios ao setor público.

Por isso, para o processo de planificação - compreendido êste não como um fim, mas como meio de desenvolvimento integral - , se há de promover um sentimento de participação e de realização em cada um $e$ em todos aquêles funcionários e empregados que, direta ou indiretamente, intervêm na planificação.

Um bom sistema de planificação deve permitir um fluxo e refluxo de informação desde a unidade central até as unidades setoriais $e$ até os mais baixos niveis operativos de cada uma das repartições, organismos e instituições públicas. Sua organização há de ser concebida como um sistema de vasos comunicantes que evite o isolamento de algumas unidades e que a agência central se converta em mera tôrre de comando; pelo contrário, esta há de ser como um órgão de serviço, - ponto estratégico aonde se coordenam os diversos trabalhos de todo o setor público.

Dessa forma pode-se obviar o que acontece quando os planos globais se formulam sem consulta, sem a devida participação das unidades setoriais, ou desconhecendo as possibilidades de realização dos niveis operativos. Ao contrário, nem sempre os que têm a responsabilidade executiva nos niveis de operação ou nas unidades setoriais desenvolvem suas atividades conforme os planos globais aprovados, ou o que é mais grave, atuam sem planos de qualquer natureza ou, quando o fazem, é, freqüentemente, de forma mecânica e empírica.

A informação a que anteriormente se fêz referência deve complementarse com o desenvolvimento de procedimentos que permitam ir fazendo uma avaliação periódica e oportuna da forma em que se estão executando os planos.

Paralela e adicionalmente à formulação de planos globais e setoriais devem-se prever e definir tôdas as medidas necessárias para a implementação dos mesmos, tais como o uso dos mecanismos governamentais de política, a definição concreta de programas e projetos, a adequação do marco jurídico e administrativo, etc.

\section{O sistema de orçamento}

Para a formulação dos orçamentos públicos existe uma nova concepção orçamentária que é o do Orçamento por Programas. Essa técnica "... presta particular atenção às coisas que um govêrno realiza, mais do que as coisas que adquire..."7 Semelhante enfoque transforma o orçamento em um plano operativo de curto prazo para a realização das funções do setor público, sistema que pressupöe uma integração efetiva ao processo de planificação. Dessa forma se facilita a unidade de ação em todo êsse setor, pois que o orçamento se converte em

7. Naçб̋es Unidas, “Orçamento, Programa e Execuçáo por Atividades" (Documento da ONU, 1959). 
um instrumento que tende a disciplinar as atividades da administração pública.

Em sua estrutura, o documento orçamentário mostra as diversas funções, programas, atividades e projetos que se cumprem através das diversas dependências do govêrno e demais Instituições públicas; durante sua execução, o sistema busca uma maior eficiência administrativa através de uma melhor combinação dos recursos humanos, materiais e financeiros alocados ou distribuídos a cada unidade programática.

Ao superar esta técnica as limitações do orçamento tradicional - por constituir-se êste bàsicamente de uma lista dos gastos, pondo sua atenção exclusivamente no contrôle legal dos mesmos - foi introduzida na maioria dos países da América Latina como um instrumento necessário e complementar ao processo da planificação.

Para o eficaz desenvolvimento dêste sistema requer-se sua institucionalização através de uma organização orçamentária em forma piramidal em cujo ápice encontra-se o órgão central de orçamento dos ministérios e das instituições e cujas bases são constituídas pelas unidades setoriais de orçamento dos ministérios e das instituições descentralizadas funcional e geogràficamente. A agência central de orçamento é a encarregada de vigiar - cumprimento das normas orgânicas orçamentárias para a totalidade do setor público - as quais são dadas pela lei e seus regulamentos - , através de todo o ciclo orçamentário, desde a programação até a liquidação e avaliação do cumprimento dos programas.
A direção centralizada do processo orçamentário se traduz na autoridade normativa que deve possuir o órgão central de orçamento. Fazendo uso dessa autoridade o órgão central pode emitir instruções ou diretrizes técnicas para tôda a organização orçamentária do setor público quanto à formulação, programação, execução, etc., do ciclo orçamentário.

Modificar-se-ão, assim, as atitudes, práticas e vícios dos organismos incumbidos da administração orçamentária.

Para atingir êsses objetivos, também devem fazer-se mudanças substanciais nos organismos que cumprem certas funções muito relacionadas com a atividade orçamentária, como os órgãos de contrôle e as auditorias fiscais, a contabilidade, as administrações tributárias ou de receitas públicas, e demais organismos financeiros, para adaptar seus sistemas à natureza e às necessidades que surgem de um orçamento programático.

Tôdas essas entidades do processo orçamentário devem colaborar para o cumprimento das políticas e programas, já que o orçamento é um dos principais instrumentos da planificação, para obter ou atingir as metas do desenvolvimento referentes ao setor público.

O órgão central de orçamento é o responsável pela formulação do orçamento do setor público, baseada nos projetos de orçamento formulados por cada uma das unidades orçamentárlas dos ministérios e entidades descentralizadas funcional e geogràficamente. Esses projetos são formulados tendo em conta as pautas dadas pelo órgão central sôbre a elaboração e 
apresentação uniforme dos programas e, quanto aos níveis de atividade, tomando como ponto de referência os planos setoriais de desenvolvimento a médio e a longo prazos.

\section{O sistema de modernizaçăo administrativa}

Laureano López Rodó afirmou que é preferivel denominar-se "modernizaçăo" e não "reforma" ao processo de aperfeiçoamento que orientará as tarefas de atualização para compatibilizar as estruturas e os procedimentos administrativos com os objetivos e planos de desenvolvimento.

Nas palavras do citado López Rodó: “... nosso trabalho é construtivo mais do que revisionista. Interessa-nos muito menos o passado do que o futuro. O que acima de tudo nos importa é estabelecer um equacionamento nôvo de nossa Administração que a torne mais ágil e mais eficaz. Nossa tarefa tem um acentuado signo positivo: aspira ao melhoramento da Administração em todos os seus aspectos e, em primeiro lugar, ao melhoramento da situação dos funcionários."8

Esse processo de modernização da administração tende a introduzir nos tradicionais e nem sempre técnicos critérios de organização do setor público, os conceitos da administração científica. Harmoniza assim a teoria com a sua aplicação prática e através dêsse meio permite que se conservem e mantenham mais fàcilmente renovadas as bases da organização formal e os respectivos procedimentos que the dão agilidade, para que ela ajuste suas estruturas e métodos às variáveis e mutáveis exigências do desenvolvimento.
O processo de modernização administrativa evita as mudanças bruscas e as transformações improvisadas e, dentro de seus planos, estabelece as etapas para que ela se leve a efeito em sequêencia lógica e oportuna, com os requisitos e necessidades dos outros planos, dos recursos orçamentários e do pessoal disponível.

"A análise da situação administrativa e a determinação de objetivos, metas e recursos deve levar-se a efeito com a mesma metodologia utilizada no estabelecimento dos planos de desenvolvimento econômico e social.

Deve iniciar-se com a elaboração de diagnósticos da situação administrativa geral de cada país para passar, imediatamente, a diagnósticos mais pormenorizados por setores, até chegar, em uma terceira etapa, a diagnósticos institucionais. Isto permitirá conhecer e analisar a fundo os problemas administrativas gerais e os que são privativos de cada setor, $e \mathrm{em}$ detalhe, os de cada unidade participante no processo de planificação do desenvolvimento nacional.

Sôbre a base dêste diagnóstico e análises pormenorizadas da realidade administrativa, deve empreender-se o planejamento administrativo global do setor público, o planejamento administrativo setorial e a reforma administrativa institucional, sempre de acôrdo com as necessidades da planificação econômica e social de cada país.

O não emprêgo de um método como o acima descrito para analisar a administração ensejará o perigo das reformas isoladas que não proporcionam

8. López Rodó, "Primera Semana de Estudios sobre la Reforma Administrativa", Madrid, 1958. 
resultados, a julgar pela magnitude dos problemas remanescentes, que subsistem."9

Assim como existem planos para diversificar e incrementar as exportações, ou o aperfeiçoamento cultural através da alfabetização em massa, assim também há que se planejar com cuidado a modernização administrativa, que é mais que reforma e multo mais que os estudos denominados "organizaçăo e métodos" que tendem a pequenas melhorias técnicas.

A experiência de vários países demonstra que a modernização global há de realizar-se por etapas e escoIhendo aquelas instituições, procedimentos ou sistemas, aos quais se Ihes outorgue prioridade, por constituir elementos chaves para o desenvolvimento. Também pode-se atribuir prioridade a trabalhos de modernização administrativa que, sem estar estreita e diretamente vinculadas com os planos de desenvolvimento em execução, em determinado período, terão projeções positivas ou negativas, a médio e longo prazos. Tal é o caso do estabelecimento de um sistema de mérito e de carreiras administrativas para todo o setor público, a organização de um moderno sistema tributário municipal, etc.

E importante que a modernização administrativa não procure resolver problemas particulares não contemplados nos planos. Fazê-lo poderia implicar o início de uma incursão num labirinto. Sem embargo, dentro de uma determinada planificação, podem-se iniciar os trabalhos de melhoramento, do particular ao geral, ou, ao inverso, em ambos os sentidos, isto é, de unidades dependentes a ministérios ou instituições; de setores a sistemas; de pequenos organismos a grandes estruturas; de tarefas a atividades institucionais ou a funções de natureza similar, tais como, por exemplo, as que realizam os diferentes componentes do programa educativo nacional, o do programa de seguro social, etc.

A modernização administrativa demanda profissionais e técnicos de formação diversificada e múltipla experiência; é indispensável programar dentro dos planos de ação, - que serão de responsabilidade operativa do sistema de pessoal - , casos de adestramento no serviço e de formação profissional complementar.

"O pessoal treinado em administração para o desenvolvimento é sumamente escasso na América Latina. Quando existe, está melhor capacitado para realizar análises microadministrativas, para resolver problemas de sistemas e procedimentos. Existe muito pouca preparação e experiência em análises macroadministrativas gerais ou setoriais; sòmente um reduzido número de técnicos tem alguma experiência em formular políticas para a modernização integral administrativa do setor público. Este grande vazio se irá preenchendo à medida que o aparato administrativo se adeque às funções de planificação e de orçamento nacional, com o propósito de lograr o cabal cumprimento dos planos gerais de desenvolvimento."10

Como em muito poucos paises latino-americanos existe sistema de mérito e carreiras, a estabilidade do pes-

9. Lic. José Marla Jácome, "Problemas da Administraçấo Pública nos Países em Desenvolvimento da América Latina", ICAP, 1967.

10. "Problemas da Administraçấo Pública nos Países em Desenvolvimento da América Latina", op. cit. 
soal. de direção superior, intermédia e técnica não é comum. Por êsse motivo o processo de decisões não tem a maturidade, experiência e agilidade que se requer. Essa falta de segurança nos cargos superiores se agrava pela ausência de políticas de pessoal que propiciem o reconhecimento justo e relacionado com o mercado profissional, de salários, que motivem e estimulem trabalhar com o Govêrno. Conseqüentemente, a modernização administrativa sofre com freqüência interrupções, estagnaçöes e paralisaçōes, ocorrendo, em alguns casos, regresso a estruturas e métodos administrativos superados, quando acontecem modificações nos níveis de direção.

O treinamento para a modernização administrativa, e também para todos os outros sistemas prioritários objetos de estudo e para os outros segmentos do setor público, especialmente do govêrno, há de considerar, de preferência, a quem ou aos que ocupam cargos de direção inferior e intermédia, pois êstes têm maiores possibilidades de estabilidade que os de dlreção superlor e ajudam assim, uma vez treinados e motivados, a melhor colaborar e são, ademais, um fator multiplicador para os níveis superiores e inferiores. A par do trabalho dos generalistas e analistas administrativos será necessário que as equipes de modernização sejam integradas, em cada caso, por especialistas "substantivos" que possuam conhecimentos administrativos adicionals aos de sua própria profissão ou técnica.

Em alguns países latino-americanos a modernização deverá começar pelo próprio "Gabinete" do Chefe do Poder Executivo, estender-se aos outros níveis de decisão política e, em segul$\mathrm{da}$, aos demais niveis de direção e operação. Quando o processo é o inverso, isto é, de baixo para cima, corre-se o perigo e o risco de não contar com a compreensão e 0 respaldo político necessário ou que se esteja em um processo de racionalização para propósitos não definidos, não atualizados ou injustificados.

“... deve-se criar a consciencia de que a administração, como meio para atingir os fins sócio-econômicos, é importante; de outro modo, será difícil suscitar interêsse pela adoção de medidas efetivas destinadas a melhorar o rendimento administrativo. Essa modificação de atitude e essa tomada de consciência devem partir do nivel supremo de govêrno, porque a administração é, fundamentalmente, uma projeção e um instrumento dos processos políticos... e não é possível obter progressos importantes em matéria de reformas administrativas sem 0 apolo de quantos detêm o poder politico efetivo.

$\mathrm{Na}$ realidade, o impulso para o progresso administrativo deve provir dos próprios dirigentes do país."11

A experiência também demonstra a imperiosa necessidade de contar com um marco jurídico e com um sistema de procedimentos jurídicos capazes de responder ràpidamente às exigências do processo de desenvolvimento e a modernização administrativa.

Corresponde ao órgão central do sistema de modernizaçăo: investigar, formular programas integrais e expedir normas técnicas para as unidades

11. Secretaria da Comissáo Econômica para a Asla e O Extremo Oriente, ONU, 1967. 
setoriais, as quais, assim orientadas, deverão realizar o mesmo em seu próprio âmbito.

\section{O sistema de pessoal}

O desenvolvimento consiste, em um alto grau, em uma mudança de atitude que permita não sòmente alcançar horizontes ou metas mais amplas de caráter econômico e melhor distribuição dos benefícios sociais do incremento, mas, ao mesmo tempo que "la gente se abra hacia el futuro".

Isto é, a fôrça ou o fator fundamental do desenvolvimento é o homem, cada um dos homens de um país.

"O eficiente funcionamento de qualquer instituição humana depende, em última análise, da qualidade dos sêres que a integram. O Govêrno, que antes de tudo é uma instituição humana na qual se reflete o conjunto, eternamente variável, das fôrças, faIhas, esperanças, temores e aspiraçöes dos homens, não constitui uma exceção a êssse princípio. 0 êxito ou o fracasso da gestão governamental dependem das pessoas incumbidas de levá-la a efeito."12

Para tais propósitos não sòmente - Govêrno, mas todo o Estado, no sentido amplo do têrmo (setor públi$\mathrm{co}$ ), hão de contar com um sistema do mérito e de carreiras para a administração de seu pessoal. Através do sistema do mérito e de carreiras se garante a igualdade de oportunidades, a fim de que qualquer cidadão tenha direito a aspirar a servir nesse setor público, independentemente de seu credo, de sua ideologia política, de sua raça, etc., o que equivale a um reconhecimento prático de seus direitos humanos. Essa aspiração sòmente se condiciona à demonstração de suas aptidões, conhecimentos e experiêncla por meio da aplicação de métodos técnicos de seleção, recrutamento, aproveitamento no cargo, classificaçăo, remunerações objetivas, acordes com as funções e autoridade, acessos, promoçöes, transferências, permutas, mudanças de carreira, readaptações, trelnamento, aposentadorias, pensões, etc.

Para se conseguir o estabelecimento e adequada operação de um sistema de pessoal baseado no mérito e na carreira hão de se satisfazer os seguintes requisitos, todos êles integrados em um plano:

a) instrumentos juridicos, constituidos por disposições constitucionais e legais, estatutárias, gerals, para todo o setor público, e particulares para os ministérios, dependências, organismos descentralizados e carreiras especials da função pública, tais como a docente, a judicial, a diplomática, a militar, etc.

b) determinação de uma política de pessoal congruente com as necessidades, os recursos e as aspirações do país, que não tenda a uma proteção paternalística dos empregados públicos, mas a promover o pleno desenvolvimento da personalidade dêles e reconhecimento autêntico de seus deveres e de seus direitos.

Cumpre atribuir “... importância à formulação de políticas de pessoal orientadas no sentido da resolução dos problemas com que se defronta o desenvolvimento nacional"...

A política de pessoal há de compreender, também, outros aspectos tão importantes como: a relação dos

12. Missăo Currie, "Reorganizaçăo do Poder Executivo do Govêrno da Colômbla", Bogotá, 1952. 
programas educativos nacionais com as necessidades de seleçăo e recrutamento; a relação dos programas de capacitação profissional com os planos de treinamento em serviço e capacitação complementar para prover ao Estado de mão-de-obra e pessoal especializado, a relação deverá existir entre a harmonização das escalas de salários públicos nos diferentes níveis e âmbitos com os salários do setor privado, etc.

c) Instrumentos institucionais que compõem o sistema de pessoal público, integrado por:

\section{I - órgăo central;}

II - pelas unidades setoriais de pessoal, localizadas em tôdas as diversas repartições públicas; e

III - pelo órgão judicial de direito administrativo.

O órgão central do sistema regula diretamente tôdas as unidades setoriais do Poder Executivo e, indiretamente, por meio de normas técnicas, também regula as atividades de pessoal das diversas unidades setoriais localizadas em outros Podêres do Estado e nos organismos funcional e geogràficamente descentralizados. Essas diretrizes não se emitem nem operam como ordens hierárquicas que estabeleçam comunicaçōes distintas das relações formais do respectivo âmbito institucional, aonde estão situadas as unidades setoriais. Atuam através das funções inerentes a um estado-maior, isto é: assessoria, informação, revisão e contrôle de normas por encargo do Chefe do Executivo e pela autoridade técnica e legal que possuem. Essas diretrizes permitem a aplicação central e descentralizada daqueles métodos técnicos mediante os quais se pōe em operação o sistema de mérito $\theta$ de carreiras, através das unidades setoriais que atuam assim dentro de uma mesma orientação e de uma mesma política de pessoal, mas que guardam cada uma suas características próprias e a relativa independência que devem possuir. $O$ órgão judicial de direito administrativo está destinado a conhecer e deliberar sôbre todos os conflitos individuais e coletivos em matéria de administraçăo pública. Geralmente é organizado com um critério pluripessoal como um tribunal, junta, comissão, conselho ou côrte que trabalha no âmbito do Poder Executivo, com absoluta independência.

\section{B. Os sistemas centrais auxiliares}

\section{O sistema estatístico}

A estatística proporciona dados sôbre diversos fatôres de população, produção, distribuição, clima, transações de comércio internacional, indices de preços, etc. Fá-lo por melo de investigações periódicas de caráter censitário e de amostragens ou através da utilização de informações administrativas, as quais se constituem em séries estatísticas.

A organização das investigações periódicas requer um grande esfôrço humano e financeiro, pois são muitas as pessoas que têm de participar nesse processo de recopilação e nas etapas de apuração, codificação, tabulação, análise e publicação dos dados. Usualmente êsse trabalho se realiza no órgão central de estatística, mas requer o concurso de muitas outras dependências e organismos do Estado, constituindo a administração censitária um desafio para o país pelo seu volume e características. 
A recopllação das séries estatísticas - que também se faz periòdicamente, via de regra mensalmente $e$ que logo são tabuladas por trimestres, semestres e para cada ano, exige outro tipo de organização. A fonte dos dados está nas unidades setoriais do sistema, cada uma das quais freqüentemente origina as estatísticas de seu âmbito $e$ as processa, muitas vêzes até produzir suas próprias tabulações e publicações, quando o sistema é "descentralizado ou semi-centralizado", tôdas as quais obedecerão às diretrizes emitidas pelo órgäo central ou recomendadas e postas em execução através dêle. Também lhe cabe difundir em todo o sistema as recomendações ou acôrdos estatísticos originados nos organismos internacionais aos quais incumbe 0 encargo de estabelecer as comparações indispensáveis, nos aspectos referentes a denominações, nomenclaturas, metodologia, tabulações mínimas e assim por diante.

Compete ao órgão central do sistema estatístico cuidar dessa comparabilidade com fins nacionais, regionais, interamericanos $\theta$ mundiais.

As estatísticas contínuas e censltárias, e especialmente estas últimas, são um processo dispendioso mas cuja utilidade o justifica. Para tanto há de se ter um grande sentido de propósito e uma adequada planificação em todos os seus processos. A experiência de vários paises da América Latina demonstra que mui freqüentemente se faz o esfôrço e se investem grandes somas na etapa de coleta, mas não nas etapas dos processos manuais e mecânicos, análise d publicação dos resultados.
O órgão central do sistema deverá ter capacidade técnica e administrativa para assessorar as diferentes unidades setoriais nos trabalhos de investigaçăo, processamento mecânico, publicação de suas séries no anuário, estatístico e nos boletins periódicos que o sistema publicar.

A aquisição ou aluguel dos modernos equipamentos eletrônicos de processamento de dados e a grande capacidade de trabalho que oferecem não justificam sua proliferação nas diferentes unidades setoriais do sistema.

O órgão central deverá ajudar no processo de tabulaçăo, podendo-se realizar a perfuração das investigações e das estatísticas contínuas nas diferentes unidades setoriais. Um sistema estatístico moderno há de publicar atualizadamente os seus dados e para isso o órgão central prestará sua colaboração às unidades setoriais, o qual constitui um magnífico meio de coordenação, pois um bom plano de quadros para serem incluídos regularmente no anuário e nos boletins periódicos facilita a integração dos trabalhos desde a fase nicial.

O sentido de propósito que hão de ter as estatísticas refletir-se-á também na estrita vinculação que hão de manter com a planificação, para definir o conteúdo das investigaçöes, os trabaIhos de análise, os quadros a serem publicados, etc. Isto é de especial importância para aquêles dados que se requerem para determinar as metas, avaliar os resultados da planificação $\theta$ para orientação das outras atividades dos sistemas prioritários do desenvolvimento.

A organizaçăo de um conselho naclonal de estatistica pode servir como fator de estímulo e aprimoramento, in- 
tercâmbio de idéias, experiências, etc. a fim de que o órgão central do sistema conduza com eficiência o trabaIho estatístico nacional e fixe critérios para todo o sistema.

\section{O sistema de contabilidade pú-} blica

Como é sabido, a contabilidade constitui o conjunto de princípios, normas e procedimentos que permitem o registro sistemático das operações, transações, estado e conseqüênclas financeiras da administração, para prover aos organismos diretores dos elementos de análise que permitam um adequado conhecimento da situação financeira da organização ou emprêsa com o objeto de levar a cabo uma decisão acertada.

É evidente que não poderia administrar-se adequadamente o setor público de um país se se desconhece o valor do patrimônio público, o montante real de suas receitas e recursos, dos gastos correntes e de capital e o detalhe das demais transações financeiras. A contabilidade pública trata das normas, convençōes e métodos para registrar as operaçőes, estados financeiros e orçamentários das entidades de direito público que administram os diversos organismos do setor público e as emprêsas em que o Estado tenha participação especial.

A planificação integral da economia pôs de manifesto a necessidade de estabelecer um sistema composto por um organismo central e unidades setoriais de caráter operativo.

O primeiro se encarrega de ditar as normas contábels e exerce a vigilâncla de seu cumprimento, para fazer possível a consolidação das operações financeiras de todo o setor público, de um balanço geral e estados econômicos e financeiros dos setores que o compõem. As unidades setoriais de contabilidade executam seus encargos no próprio âmbito, com o detalhe que se requer.

Desta forma se cumprem melhor os objetivos da contabilidade pública ao capacitar a um organismo central para fornecer informações de caráter financeiro, fidedignas e oportunas, a diferentes setores e para fins diversos. Esta necessidade tem sido reconhecida nas diferentes reuniōes técnicas sôbre problemas de orçamento, contabilidade e fiscalização, celebradas pelas Nações Unidas, em várias partes do mundo, recomendando que devido às mudanças ocorridas no alcance $\theta$ conteúdo das operações públicas durante os últimos anos, é necessário centralizar e introduzir reformas na contabilidade pública, a fim de melhor servir as demandas que surgem com a planificação e o orçamento por programas.

O órgão central do sistema deve regular, por melo de normas técnicas, as atividades contábeis das unidades setoriais do govêrno central e dos organismos descentralizados, devendo se submeter tôdas elas ao mesmo plano de contas e à mesma metodologia que se estabeleça centralmente. Da mesma maneira o órgão central deve prestar assessoria a tôdas as unidades do sistema $e$ as unidades setoriais por sua vez facilitam a agência central de informação periódica que requer a consolidação dos estados contábeis.

o sistema central de contabilidade para um funcionamento eficaz também tem que atuar dentro de seu âmbito em perfeita coordenação com os demais sistemas centralizados, especial- 
mente com os de orçamento, compras e abastecimento. Igualmente deve atuar em estreita colaboração com os organismos de Tesouraria e Contrôle ou Côrte de Contas (Tribunais) geralmente dependentes, o primeiro dos Ministérios da Fazenda e os segundos do Poder Legislativo.

\section{O sistema de compras, abas-} tecimento e armazenamento

É êste o último dos sistemas prioritários para a administração do desenvolvimento; a ordem em que se trata não significa, sem embargo, que tenha menor importância que os outros sistemas auxiliares ou assessôres centrais anteriormente mencionados.

Um sistema de compras, abastecimento e armazenamento reduz os custos de operação, aumenta o rendimento total e melhora as relações dos diferentes organismos do Estado com os abastecedores e usuários públicos e privados.

A experiência demonstrou que não é conveniente, como algumas vêzes acontece, centralizar, em um único órgão, tôdas as compras, fornecimentos e armazenamento dos bens adquiridos. É preferivel que o órgão central, na forma semelhante a dos outros sistemas prioritários já indicados, dê as normas e regule os métodos, procedimentos e práticas, propiciando, ao mesmo tempo, que a ação se tome nos respectivos níveis de operação de cada um dos âmbitos aonde existem unidades setoriais.

Algumas vêzes acontece ser mais conveniente que as aquisições se façam centralizadamente naqueles casos em que se podem comprar bens de uso comum e generalizado; ao fazê-lo, assegura-se uma qualidade mais unt- forme e preços mais vantajosos. Também facilita posteriormente o cumprimento das requisições das diferentes dependências ou organismos interessados, ao permitir que os pedidos se satisfaçam diretamente, sem necessidade de ter de recorrer, em cada caso, a novas licitações e pequenos pedidos.

O sistema permite a uniformidade nas aquisições de certos bens, tais como equipamentos de escritórios, veiculos, móveis, etc. com o que se facilita, economiza e barateia a conservação dos mesmos, a aquisição e a organização do serviço de consertos e manutenção, ante a possibilidade de se contar com um inventário de peças sobressalentes que se pode usar mais amplamente.

Quando as compras se fazem sistematizadas, ainda que com um critério flexivel que pode, inclusive, aconselhar certo grau de descentralização, além da obtenção de menores custos, obtém-se um aumento do rendimento e uma melhoria das relações da unidade interessada com os fornecedores.

No concernente à operação do sistema de compras, abastecimento e armazenamento podem-se fazer idênticas recomendações às anteriormente indicadas para os outros sistemas prioritários, ou seja, estabelecer normas gerais centrais para lograr a coordenação das atividades $\mathrm{e}$ a maior independência possivel para as unidades setorlais de operação, dentro de tais normas, de maneira a ser estimulada a respectlva iniciativa.

Observaçá: Documento oficial do ICAP para o Seminário das Naçóes Unidas Söbre os Sistemas Prioritários para a Administração do Desenvolvimento - Dezembro de 1958, Săo José, Costa Rica. 